http://dx.doi.org/10.11646/zootaxa.3841.3.6

http://zoobank.org/urn:lsid:zoobank.org:pub:5308906B-BA1E-47AB-819C-9B449ACD9D4B

\title{
A new genus of Psychodinae (Diptera, Psychodidae) from phytotelmata in a Honduran cloud forest
}

\author{
FREDDY BRAVO ${ }^{1}$, DANILO CORDEIRO ${ }^{1} \&$ MERLIJN JOCQUE ${ }^{2,3}$ \\ ${ }^{l}$ Departamento de Ciências Biológicas, Universidade Estadual de Feira de Santana, Av. Universitária s/n, 44031-460, Feira de San- \\ tana, BA, Brazil.E-mail:fbravo@uefs.br \\ ${ }^{2}$ Jessica Ware Lab, Rutgers, the State University of New Jersey, 195 University Ave, Newark, NJ, 07102, US \\ ${ }^{3}$ Operation Wallacea, Hope House, Old Bolingbroke, Lincolnshire, UK
}

\begin{abstract}
Larvae of a new species of Psychodinae, Moruseodina cusucoensis gen. et sp. nov., were collected during a biodiversity survey of aquatic invertebrates in plant held water bodies (phytotelmata) in Cusuco National Park, Honduras. The fourth instar larva, pupa and adult male are described based on reared material. The new species was difficult to place in an existing genus, thus a new genus name is proposed. Based on similarities in morphological characteristics, ecology and distribution, the species Moruseodina superba comb. nov. and Moruseodina conspicua comb. nov. are transferred from Telmatoscopus Eaton, 1904 to the new genus.
\end{abstract}

Key words: Moruseodina, Paramormiini, Central America, moth flies, new species.

\section{Introduction}

Moth flies (Diptera: Psychodidae) are a diverse family with approximately 2900 species described (Curler \& Courtney 2009; Wagner \& Ibáñez-Bernal 2009). Currently 274 species are recorded from Central America (Wagner \& Ibáñez-Bernal 2009), but this number is likely to increase. The ecology of psychodid larvae is diverse and largely unknown, but in general they are detritivores. Psychodid larvae can be found in a variety of aquatic and semi-aquatic habitats such as rotting wood, carrion, fungi and dung (Wagner 1997). Larvae of some Psychodinae are adapted to live in phytotelmata (Quate \& Vockeroth 1981); typically recorded from water-filled tree holes, bromeliad tanks, bamboo internodes and a range of plant axils (Kitching 2000; Frank et al. 2004; Frank \& Lounibos 2009; Bravo et al. 2010).

During a biodiversity survey of freshwater invertebrate communities in phytotelmata in Cusuco National Park, Honduras, an undescribed species of Psychodidae was commonly observed in tree holes and bromeliads. Morphological characteristics of the adult antennae and maxillary palpi suggested a close association with members of the genus Lepiseodina Enderlein, 1936. However, based on the morphology of male genitalia we suggest that this species would be more appropriately placed in a new genus of Psychodidae, herein described. Two Neartic species, Telmatoscopus superbus (Banks, 1894) and Telmatoscopus conspicuus (del Rosario, 1936) are also transferred from Telmatoscopus Eaton, 1904 to the new genus.

\section{Material and methods}

Specimens were collected during an expedition organized by the ecovolunteer driven conservation organization Operation Wallacea to Cusuco National Park (CNP), between 12 July and 22 August 2006. CNP (Fig. 1) is situated in northwestern Honduras, within the Merendon Mountain range. The core zone of the park consists of lower montane tropical rain forest (a mix of primary and secondary), with patches of primary cloud forest and upper 


\section{Acknowledgements}

We would like to thank Humberto Mendes for help in the field and raising the larvae. Our gratitude goes to Rüdiger Wagner, Jan Ježek and one anonymous reviewer for comments on an earlier version of this manuscript. FB received financial support from CNPq (471199/2009-5) and has a research grant from CNPq (302120/2009-2).

\section{References}

Banks, N. (1894) Some psychodidae from Long Island, N.Y. The Canadian Entomologist, 26, 329-333. http://dx.doi.org/10.4039/ent26329-12

Bravo, F., Silva, P. \& Bastos, S. (2010) A new Brazilian of Psychoda Latreille, 1796 (Diptera, Psychodidae) collected in a bromeliad. Biota Neotropica, 10, 167-169. http://dx.doi.org/10.1590/s1676-06032010000200021

Bravo, F., Souza, I., Santos, C.B. \& Ferreira, A.L. (2011) Three new species of Telmatoscopus Eaton, 1904 (Diptera, Psychodidae) from Brazil. Zootaxa, 2802, 34-40.

Cumming, J.M. \& Wood, D.M. (2009) Adult morphology and terminology. In: Brown, B.V., Borkent, A., Cumming, J.M., Wood, D.M., Woodley, N.E. \& Zumbado, M.A. (Eds.), Manual of Central American Diptera. Vol. 1. NRC Research Press, Ottawa, Ontario, Canada, pp. 9-50.

Curler, G.R. \& Courtney, G.W. (2009) A revision of the world species of the genus Neotelmatoscopus Tonnoir (Diptera: Psychodidae). Systematic Entomology, 34, 63-92. http://dx.doi.org/10.1111/j.1365-3113.2008.00439.x

Curler, G.R. \& Moulton, J.K. (2012) A review of Nearctic Clytocerus (Diptera: Psychodidae: Psychodinae). The Canadian Entomologist, 144, 186-195. http://dx.doi.org/10.4039/tce.2012.16

Del Rosario, F. (1936) The American Species of Psychoda (Diptera: Psychodidae). The Philippine Journal of Science, 59, 85-148.

Enderlein, G. (1937) Klassifikation der Psychodiden (Dipt.). Deutsche Entomologische Zeitschrift, year 1936, 3, 81-112. http://dx.doi.org/10.1002/mmnd.48019360301

Frank, J.H. \& Lounibos, L.P. (2009) Insects and allies associated with bromeliads: a review. Terrestrial Arthropod Reviews, 1, $125-153$. http://dx.doi.org/10.1163/187498308x414742

Frank, J.H., Sreenivasan, S., Benshoff, P.J., Deyrup, M.A., Edwards, G.B., Halbert, S.E., Hamon, A.B., Lowman, M.D., Mockford, E.L., Scheffrahn, R.H., Steck, G.J., Thomas, M.C., Walker, T.J. \& Welbourn, W.C. (2004) Invertebrate animals extracted from native Tillandsia (Bromeliales: Bromeliaceae) in Sarasota County, Florida. Florida Entomologist, 87, $176-185$. http://dx.doi.org/10.1653/0015-4040(2004)087[0176:iaefnt]2.0.co;2

Halffter, G. (1987) Biogeography of the montane entomofauna of Mexico and Central America. Annual Review of Entomology, $32,95-114$. http://dx.doi.org/10.1146/annurev.en.32.010187.000523

Ježek, J. (1989) Contribution to the taxonomy of the genus Telmatoscopus Eat. (Diptera, Psychodidae). Acta Musei Nationalis Pragae, 44, 75-104.

Ježek, J. (1990) Contribution to the taxonomy of some genera of Paramormiine moth flies (Diptera, Psychodidae) with description of a new genus Karakovounimerus. Acta Entomologica Musei Nationalis Pragae, 43, 129-157.

Ježek, J. (2004) New and interesting moth flies (Diptera, Psychodidae) from protected and underestimated natural areas of the Czech Republic. Journal of the National Museum (Prague), Natural History Series, 173, 113-128.

Kitching, R.L. (2000) Food webs and container habitats: the natural history and ecology of Phytotelmata. Cambridge University Press, Cambridge, 448 pp.

Quate, L.W. (1955) A revision of the Psychodidae (Diptera) in America North of Mexico. University of California Publications in Entomology, 10, 103-273.

Quate, L.W. \& Brown, B.V. (2004) Revision of Neotropical Setomimini (Diptera: Psychodidae: Psychodinae). Contributions in Science, Natural History Museum of Los Angeles County, 500, 1-117.

Quate, L.W. \& Vockeroth, J.R. (1981) Psychodidae. In: McAlpine, J.F., Peterson, B.V., Shewell, G.E., Teskey, H.J., Vockeroth, J.R. \& Wood, D.M. (Coords.), Manual of Nearctic Diptera. Vol. 1. Monograph 27. Research Branch, Agriculture Canada, pp. 293-300.

Santos, C.B. \& Curler, G.R. (2014) Four new species of Tonnoira Enderlein (Diptera: Psychodidae: Psychodinae) from the Brazilian Atlantic forest. Zootaxa, 3760, 463-470. http://dx.doi.org/10.11646/zootaxa.3760.3.13

Vaillant, F. (1971-1983) 9d. Psychodidae-Psychodinae (not finished). In: Lindner, E. (Ed.), Die Fliegen der palaearktischen Region. 10 Vols. Stuttgart., 287 (1971), pp. 1-48; 291 (1972), pp. 49-78; 292 (1972), pp. 79-108; 305 (1974), pp. 
109-142; 310 (1975), pp. 143-182; 313 (1977), pp. 183-206; 317 (1978), pp. 207-238; 320 (1979), pp. 239-270; 326 (1981), pp. 271-310; 328 (1983), pp.311-357.

Wagner, R. (1997) Family Psychodidae. In: Papp, L. \& Darvas, B. (Eds.), Contributions to a Manual of Palaearctic Diptera. Vol. 2. Nematocera and Lower Brachycera, Science Herald, Budapest, pp. 205-226.

Wagner, R. \& Ibáñez-Bernal, S. (2009) Psychodidae (sand flies, and moth flies or owl flies). In: Brown, B.V., Borkent, A., Cumming, J.M., Wood, D.M., Woodley, N.E. \& Zumbado, M. (Eds.), Manual of Central American Diptera. Vol. 1. National Research Council of Canada, Ottawa, pp. 319-332.

Wagner, R., Adler, P.H. \& McCreadie, J.W. (2010) Description of a new species and redescriptions of two known species of the genus Telmatoscopus Eaton (Diptera: Psychodidae) from Alabama, USA. Studia dipterologica, 17, 73-79. 